\title{
20
}

\section{Uganda's schools: do these need computers?}

\author{
A.P. Beauchamp \\ P.O. Box 231, Chake Chake \\ Pemba \\ Tanzania
}

\begin{abstract}
Uganda is a third world country which, in common with its neighbours in Africa, has been infiltrated by computers in business, commerce and the nongovernmental agencies operating there. The question therefore arises whether schools in Uganda should adopt the use of computers in the curriculum. This paper looks at the state of Uganda and its educational system and considers the relevance of having computers in its schools. The example of a Kenyan project is used to highlight some problems which might occur, and some conclusions are drawn as to the type of innovation which might be appropriate for Uganda. The main outcome is the conviction that inevitably computers will be placed in some secondary schools in the future. When this will be depends on many complex factors which are both financial and political.
\end{abstract}

Main conference themes: developing countries

Educational areas: secondary education

Study topics: computer literacy

Secondary keywords: curriculum policies, government 


\section{INTRODUCTION}

The author spent four years training teachers in Uganda, and has considerable experience in the use of computers in schools in England. Uganda is a country in East Africa which has been devastated by internal conflict and is among the dozen poorest countries in the world. Nevertheless, in common with other countries in a similar position, Uganda finds in its capital multinational businesses, international airlines, banks, expatriate nongovernmental organizations and aid agencies, all using computers. Its own government is also encouraged by external pressures to computerize its management procedures and of course Ugandan businesses too will be installing computers in their factories and offices. As a result of this influx of new technology there is a shortage of the skills amongst the indigenous population necessary to take advantage of the job opportunities offered by these computer users.

The question then arises as to whether it is appropriate for schools in such a country as Uganda to include information technology in their curriculum. In the developed world computers now occupy a place in virtually all secondary schools. Why is this? Do the factors which influenced their introduction into the schools of the developed nations, also apply equally in a less developed country? The discussion of these questions in this paper is based on [1].

\section{The state of the education system}

Uganda has been chosen to exemplify the general case of countries which are economically underdeveloped. In common with many colonial states and protectorates Uganda's education system evolved from missionary incursion into limited areas and then developed along elitist lines designed largely to benefit the ruling classes. Despite attempts to remedy the situation in the early 1950s even this educational provision was insufficient to support the needs of an Africanized administration at independence in 1962. Though plans were made for relevant educational provision for the mass of the population, economic progress which reached a peak in 1971, was never sufficient to support such a system. Internal armed conflict and a succession of leaders, such as Obote and Amin who were more preoccupied with preventing armed insurrection than with social policies, reduced still further the effectiveness of the existing schools.

In Uganda the average life expectancy at birth is 49 years, the fertility rate is 7.3 births per woman and the population has more than doubled between 1970 (9.6 million) and 1991 (19.5 million).

It is only since 1986 that it has been possible for Uganda to look at its education system and begin to rebuild it in a manner which will benefit economic progress. Before considering more specifically the question of 
computers in schools, it is worth taking a broader look at the state of the education system into which it may be proposed to place them.

\section{The schools}

In Uganda there is a whole range of schools from quite high quality academic schools to those with only part-time and unqualified teachers working in temporary buildings. The better schools are very few and located most often in the larger centres of population. The bulk of schools in the country conforms to a pattern which the majority of Ugandans would recognize. That is either a school built of local materials with a thatched roof and earth floor, or a colonial style school which has fallen into disrepair and has leaking roofs, broken windows and no electricity or running water, or a recently built school of brick structure with corrugated iron roof, large open window spaces and maybe concrete floors. Where electricity supplies do exist these have improved enormously in the last few years with the rehabilitation of the Owen Falls dam, currently the only major source of power. However there is still a lot of work to be done on the transmission lines since supplies, except in the area of Jinja, tend to suffer from frequent and unpredictable interruption. Many rural areas have no electricity supplies whatsoever.

Within the school buildings the lack of resources will be fairly uniform. There will be no textbooks for pupils and even a scarcity of reference texts for teachers. Paper for the teachers' use will be very limited and pupils will need to take notes in exercise books which they can barely afford to buy. Furniture is simple, locally made of varying quality and there will usually be insufficient for the whole class. Classes vary, but may contain as many as 120 pupils in a few primary and lower secondary classes and typically around 50 in most classes. In some rural areas at the other extreme there may be only five or six pupils in some classes. There will be virtually no equipment for effective science teaching, art work or other practical subjects.

\section{The staff}

Teachers in general are a dedicated core of survivors who despite the low salary and lack of status are still willing to serve the interests of pupils and education in general. Many teachers may be untrained or poorly trained, particularly in subjects such as mathematics and science where demand exceeds supply. In these subjects teachers will often be part-time and typically teach in two or three schools, often cycling between them during the day. The style of teaching is almost entirely didactic and oriented towards British O- and A-level style examinations. A large proportion of teachers needs second or third occupations in order to support their families. Subsistence agriculture is the most common, with shopkeeping and provision of local transport also quite 
common. The commitment of the staff of a school may well depend on other interests. It is therefore usually only those teaching in very successful schools which are able to pay large allowances, who devote all their attention and energies to their role in that school.

\section{The pupils}

In 1986, the last year for which figures are available, $80 \%$ of the age group started primary education, though this proportion has certainly fallen since then. The drop-out rate is very high with less than a third of pupils who start primary school, reaching the final year and less than half of these proceeding to secondary schools where the numbers are again halved by the fourth year [2]. This may be caused by domestic problems, their own or family illness, lack of money for school fees or uniform, or simply inability to cope with the academic nature of the curriculum. Besides those who drop out many others. have frequent interruptions to their schooling. Very persistent students may well be into their twenties by the time they reach the final year of secondary school. They are on the whole well disciplined, even submissive, and keen to learn. Mastery of English is often the key to a clerical job and secondary school leavers stand a chance of employment away from the subsistence agriculture of their village. This is often a key motivating factor. On their way through the system they will have to suffer a lot of inadequate teaching and even absenteeism from teachers as it is unusual for schools to be able to find a temporary replacement for a teacher who is ill or has other problems.

So the typical secondary pupil will be taught a fairly constricted examination defined curriculum by teachers who may be inadequately prepared for the task and who may themselves have significant gaps in their knowledge from their schooling. Due to the pupil's or the teachers' absence for some of the time there will be unavoidable gaps in the pupil's knowledge or the syllabus will have been crammed into the allotted time by extra lessons on Saturdays. Not surprisingly even examination results are poor and the amount of what may be described as useful education even poorer. There is however no doubting the resolve of both teachers and pupils to do their best in the difficult circumstances in which they find themselves.

\section{Why consider having computers in schools?}

There are already many computers in Uganda ranging from mainframes and minis to desk top PCs and notebooks. These are ever present in banks, businesses and offices of all kinds. This becomes particularly evident when attempting the impossible task of booking an airline ticket in Kampala during a power cut. It is to a large extent international pressures which have brought about this state of affairs. International banks, nongovernmental organizations, 
airlines and other companies have all brought the technology with them. Also the World Bank, for example, influenced the government towards the computerization of salary payment to public employees. Information technology will therefore inevitably pervade any country, however economically deprived, with connections to the world of international commerce.

Many Ugandans are involved in using computers in their everyday working life and the numbers are likely to increase as the economy improves. Training is at present most often provided as required in the workplace. Increasingly though, jobs in this field are likely to demand prior experience as a qualification for employment. As businesses develop these will require management which is aware of the potential of computers in the workplace. Computerization of small companies is hindered by all of this training from scratch. It is also prohibitively expensive for the average Ugandan to obtain training in one of the few commercial training schools in Kampala. Computer awareness and familiarization with the most common applications of information technology are therefore best provided through the educational system.

Hawkridge [3] has proposed four main rationales: the social, vocational, pedagogical and catalytic for having computers in schools. Vocational and social reasons which have been the argument above, have been commonly used to justify introduction in other countries. China for instance has averred that if it is to develop into a first rank industrialized nation, it must have computers in its schools or fail. The same reasons for considering the use of computers in schools must apply in Uganda, if only on a smaller scale.

The other two major rationales, pedagogic and catalytic, are also of some possible importance to Ugandan schools. Whilst it would be simplistic to suggest that teacher shortages in key subjects may be overcome by the use of computers, it is more feasible to suggest that teacher performance may be enhanced by the presence of computers in schools. This may come about in two ways. Courses provided by the training programme to enable teachers to incorporate computers into their teaching programmes would also require a critical appraisal of their teaching styles and approaches, and may lead to use of a greater variety of classroom methods. Secondly, many of the deficiencies in content may be made up by suitable injection of appropriate software. The use of simulations and modelling programs could, for instance, give teacher and taught some confidence in dealing with topics which may be outside their experience.

These are country specific gains. The overall advantages to students of using computers in reasonable numbers in a school have been listed by Collis 
and Carleer[4] as follows:

- increased attention span;

- positive attitudes about technology;

- increased performance on standardized tests and measures of writing proficiency;

- reduction in writing errors;

- increased enthusiasm for writing;

- increased cooperative learning;

- increased spelling skills;

- increased problem solving ability;

- more initiative;

- a deeper motivation for learning;

- spontaneous contacts for discussions;

- significant gains in handling multiple-inference problems, formulation and testing of hypotheses, data organization skills and identification of meaningful variables;

- effective use of technology as a tool.

Many other unquantifiable changes in pupils have been described and in general a change in school climate has often been a major result of the introduction of computers, with staff becoming more professionally aware and growing in insight.

\section{Computers in Kenyan schools}

Kenya has a lot more in common with Uganda than its geographical proximity. It has by African standards fairly rich large cities with foreign donor penetration and international business investment resulting in extensive use of computers. It has some relatively good schools in the urban areas, but there is also an enormous rural area with schools which are less well off.

Following a successful pilot scheme in a private Nairobi co-educational school in 1983 the Aga Khan Foundation and Apple Computers funded an expanded scheme [5] to five more widely spaced schools from the Rift Valley to Mombassa.

As a result of the pilot the project set out with five main objectives [6]:

- to improve the quality of teaching by inservice teacher education using the microcomputer as a catalyst;

- to use microcomputers as a teaching resource in school subject topics of the Kenyan secondary school syllabus; 
- to provide the pupils with a basic knowledge of new information technologies, both to aid them in their studies and to make them aware of their technological environment;

- to improve the quality of school administration through the use of appropriate information technology;

- to appoint such members of staff as required so that the school can maintain its level of educational/information technology without the need for continued support from outside.

The inservice training, despite being very effective in the pilot, had only a minor impact in the main scheme. The cascade model was adopted and only $5 \%$ of teachers in the schools received the bulk of the training which they signally failed to pass on to their colleagues. One consequence of this was that also pupils did not spend much time using the computers in a constructive and curriculum related way. For various reasons the computers in each of the schools were concentrated in a computer room which tended to divorce their use from the normal framework of lessons, and those who did use the facility, were viewed by the remainder of the staff as 'experts'.

The most successful aspect of the introduction of computers into the schools was in the administrative use. Here there was an immediate recognition that the computer could reduce the teacher's workload and make the writing of such documents as letters, hand-outs for lessons and examination papers much more efficient. As a result of such use the teachers were themselves becoming confident in the use of the technology. Though only used to any extent in the pilot school, marks for assessment recorded in databases gave the opportunity for formative evaluation of both individual and group performance. Administrative use was also valuable to the pupils, particularly those away from the cities, as possibly the only real example of the use of computers in the real world they were likely to see.

One of the main conclusions to be drawn, not only from this Kenyan experience, but also from larger initiatives in developed countries, is that the quality of inservice training is crucial to success. While it is true that many teachers take naturally to the use of computers for administration purposes, the same cannot be said of classroom use. The relative success of the pilot school in Kenya in introducing the use of computers into the normal curriculum may be seen as a direct consequence of the close proximity of supporting expertise over a sustained period, not only in the form of short courses, but also in a support role in the classroom situation. Once the programme had expanded this essential element became no longer possible with the available personnel and depletion in the quality of the outcome was the result. 


\section{THE CONCLUSIONS FOR UGANDA}

The outside pressures of international commerce make it inevitable that a sufficient number of citizens must be educated for the country to become selfsufficient in the use of information technology. In addition there are gains to be made by the introduction of computers into schools for pedagogic reasons.

The indications are that Uganda's current needs could be fulfilled by placing computers in a small number of city schools. The conditions in most of the country's schools are not yet appropriate, for example in terms of electricity supply, to contemplate their general use. By concentrating on one or two schools there are many advantages.

One benefit is that a reasonable level of support can be maintained fairly cheaply. Essentially this needs to be available on site and on call when needed over a period of years rather than months. Staff need to become confident in their personal use of computers and standard business applications One way to achieve this is for each member of staff to receive some basic instruction, have access to a machine and use it for administrative tasks. In parallel with this a programme may be run to familiarize teachers with classroom techniques related to computer use with purely pedagogical software. Only when there is some staff expertise, should the first computers be made available to pupils.

With only a small number of schools a larger number of computers may be placed in each school enabling their use to be pervasive with access when required for any pupil. This will also alleviate the competitive element which may be detrimental to equal use by girls. As with the staff there may need to be a short introductory course of instruction in the use of the machines and standard software.

In order to overcome the undesirable concentration of computers in a specialist room and taking full regard of the need for security the use of portable computers should be considered and these should preferably be of the highest current established specification to keep up with possible future developments.

The expansion of such a small scheme should proceed with caution. It is often politically desirable to include more schools for social reasons. If this is not done with the same level of support and equipment the outcome may well be very different.

\section{REFERENCES:}

1. Beauchamp, A. P. (1994) Computers in Schools: Towards a policy for Uganda. Unpublished M.A. dissertation, King's College London. 
2. UNESCO (1992) Statistical Yearbook. Paris: United Nations Educational, Scientific and Cultural Organisation.

3. Hawkridge, D. (1990) Computers in Third-World Schools: the example of China. British Journal of Educational Technology, 21 (1) pp. 4-20.

4. Collis, B. and Carleer, G. (1993) The effects of technology-enriched school intervention: a multiple case study analysis. Computers and Education, 21 (12) pp. 151-162.

5. Makau, B. M. (1990) Computers in Kenya's Secondary Schools: Case study of an innovation in education. Ottawa: IDRC.

6. Wray, B.F. (1985) Computers in Education Project Phase II, 1986-88. A proposal submitted by the Aga Khan Education Service (Kenya) to the Aga Khan Foundation, Nairobi. Quoted in [5]. 